\title{
Anesthetic Activation of Central Respiratory Chemoreceptor Neurons Involves Inhibition of a THIK-1-Like Background $\mathrm{K}^{+}$Current
}

\author{
Roman M. Lazarenko, ${ }^{1}$ Michal G. Fortuna, ${ }^{1}$ Yingtang Shi, ${ }^{1}$ Daniel K. Mulkey, ${ }^{3}$ Ana C. Takakura, ${ }^{4}$ Thiago S. Moreira, ${ }^{4}$ \\ Patrice G. Guyenet, ${ }^{1}$ and Douglas A. Bayliss ${ }^{1,2}$ \\ Departments of ${ }^{\text {Pharmacology and }}{ }^{2}$ Anesthesiology, University of Virginia, Charlottesville, Virginia 22908, ${ }^{3}$ Department of Physiology and Neurobiology, \\ University of Connecticut, Storrs, Connecticut 06269, and ${ }^{4}$ Department of Physiology and Biophysics, University of São Paulo, 05508, São Paulo, Brazil
}

\begin{abstract}
At surgical depths of anesthesia, inhalational anesthetics cause a loss of motor response to painful stimuli (i.e., immobilization) that is characterized by profound inhibition of spinal motor circuits. Yet, although clearly depressed, the respiratory motor system continues to provide adequate ventilation under these same conditions. Here, we show that isoflurane causes robust activation of $\mathrm{CO}_{2} / \mathrm{pH}$-sensitive, Phox 2b-expressing neurons located in the retrotrapezoid nucleus (RTN) of the rodent brainstem, in vitro and in vivo. In brainstem slices from Phox $2 b-$ eGFP mice, the firing of $\mathrm{pH}$-sensitive RTN neurons was strongly increased by isoflurane, independent of prevailing $\mathrm{pH}$ conditions. At least two ionic mechanisms contributed to anesthetic activation of RTN neurons: activation of an $\mathrm{Na}^{+}$-dependent cationic current and inhibition of a background $\mathrm{K}^{+}$current. Single-cell reverse transcription-PCR analysis of dissociated green fluorescent protein-labeled RTN neurons revealed expression of THIK-1 (TWIK-related halothane-inhibited $\mathrm{K}^{+}$channel, $\mathrm{K}_{2 \mathrm{P}} 13.1$ ), a channel that shares key properties with the native RTN current (i.e., suppression by inhalational anesthetics, weak rectification, inhibition by extracellular $\mathrm{Na}^{+}$, and pH-insensitivity). Isoflurane also increased firing rate of RTN chemosensitive neurons in urethane-anesthetized rats, again independent of $\mathrm{CO}_{2}$ levels. In these animals, isoflurane transiently enhanced activity of the respiratory system, an effect that was most prominent at low levels of respiratory drive and mediated primarily by an increase in respiratory frequency. These data indicate that inhalational anesthetics cause activation of RTN neurons, which serve an important integrative role in respiratory control; the increased drive provided by enhanced RTN neuronal activity may contribute, in part, to maintaining respiratory motor activity under immobilizing anesthetic conditions.
\end{abstract}

\section{Introduction}

Inhalational anesthetics produce various clinically important actions, including hypnosis, amnesia, and immobility (Eger et al., 1997). Of particular importance is the ability of these compounds to produce an immobilized state, defined by the lack of movement in response to painful stimuli (Eger et al., 1997). It is believed that different anesthetic actions involve distinct molecular targets in specific neural pathways; for immobilization, the site of action is spinal (Rudolph and Antkowiak, 2004; Grasshoff et al., 2005; Franks, 2008). Although the precise substrates for immobilizing actions are not known with certainty, it is nevertheless clear that anesthetics cause a depression of motor output that is general and profound (Kendig, 2002; Sonner et al., 2003). Despite widespread inhibition of motor function observed at immobilizing anesthetic concentrations, it is interesting (indeed crucial)

Received April 12, 2010; revised May 19, 2010; accepted May 31, 2010.

This work was supported by National Institutes of Health Grants HL74011 (P.G.G.) and GM66181 (D.A.B.). We thank Dr. Erhard Wischmeyer (University of Würzburg, Würzburg, Germany) for providing the THIK-1 construct.

Correspondence should be addressed to Douglas A. Bayliss, Department of Pharmacology, University of Virginia Health System, P.0. Box 800735, 1300 Jefferson Park Avenue, Charlottesville, VA 22908-0735. E-mail: dab3y@virginia.edu.

DOI:10.1523/JNEUROSCI.1956-10.2010

Copyright $\odot 2010$ the authors $\quad 0270-6474 / 10 / 309324-11 \$ 15.00 / 0$ that the respiratory motor system remains operational under those same conditions. Why, then, is the respiratory system relatively resistant to inhibition by inhalational anesthetics?

The networks that control breathing are generally similar to those regulating other motor outputs (for review, see Feldman et al., 2003). A rhythmogenic central pattern generator (CPG) located within the caudal brainstem drives respiratory motoneurons that control airway patency and ventilatory musculature. As with other motor systems (Kendig, 2002; Sonner et al., 2003), many neuronal elements within this system are inhibited by inhalational anesthetics (Koizumi et al., 2010); whereas this inhibition surely contributes to the well known respiratory depression during anesthesia (Evers et al., 2006), it does not readily explain the selective maintenance of respiratory motor activity. To generate ongoing regular rhythmic activity, the respiratory system receives tonic excitatory drive from multiple sources (Feldman et al., 2003). One source-the Phox2b-expressing, glutamatergic neurons of the retrotrapezoid nucleus (RTN) - is becoming recognized as critical (Feldman et al., 2003; Guyenet et al., 2009). These RTN neurons were first celebrated for their $\mathrm{CO}_{2} / \mathrm{pH}$ sensitivity and role in providing central chemoreceptor drive to the respiratory systems (Mulkey et al., 2004). Subsequently, RTN neurons were identified as a site of integration for excitatory 
inputs from many other sources (e.g., from peripheral respiratory chemoreceptors, hypothalamic and aminergic neurons) (Guyenet et al., 2009). Because direct stimulation of RTN neurons with a light-activated cation channel selectively expressed in Phox 2 b-expressing cells causes increased respiratory output (Abbott et al., 2009), it is clear that elevated firing in these neurons provides enhanced drive to brainstem respiratory control networks.

We recently found that halothane inhibits a $\mathrm{pH}$-insensitive background $\mathrm{K}^{+}$current in chemosensitive RTN neurons (Mulkey et al., 2007), an effect that should cause membrane depolarization and increase excitability. In this work, we demonstrate that action potential discharge of chemosensitive, Phox $2 \mathrm{~b}$-expressing RTN neurons is strongly enhanced by isoflurane, both in vitro and in vivo. The ionic mechanism includes activation of an unidentified $\mathrm{Na}^{+}$-dependent inward current as well as inhibition of a background $\mathrm{K}^{+}$current with properties reminiscent of THIK-1 (TWIK-related halothane-inhibited $\left.\mathrm{K}^{+}\right)\left(\mathrm{K}_{2 \mathrm{P}} 13.1\right)$ (Rajan et al., 2001). In urethane-anesthetized rats, increased RTN discharge was invariably associated with a transient increase in respiratory frequency that could even reactivate subthreshold phrenic nerve activity. These data suggest that activation of RTN neurons by inhalational anesthetics can provide enhanced excitatory drive to partially offset concomitant inhibition of other elements within the respiratory motor system, allowing maintained ventilatory activity during anesthetic-induced immobilization.

\section{Materials and Methods}

All animal use was in accordance with National Institutes of Health Animal Care and Use Guidelines and approved by the Animal Care and Use Committee of the University of Virginia. We used male or female mice and male rats for these studies.

Phox $2 b-G F P$ mice. In the present study, we used two lines of BAC transgenic mice in which enhanced green fluorescent protein (eGFP) expression is directed selectively to Phox $2 \mathrm{~b}$-expressing neurons; the derivation and salient properties of these mice have been described previously (Lazarenko et al., 2009). In both sets of mice, GFP expression is prominent in $\mathrm{pH}$-sensitive neurons of the RTN. In the medulla oblongata of the so-called B/G mouse, GFP expression is limited to a subset of RTN neurons (approximately half) and is not present in other Phox $2 b-$ immunopositive neurons. In the Jx99 mouse line, GFP expression is more widespread and appears to reflect more faithfully the overall distribution of Phox $2 \mathrm{~b}$-expressing brainstem neurons. The reason for the more restricted expression in the $\mathrm{B} / \mathrm{G}$ mouse is not known, but we found that properties of GFP-expressing RTN neurons were not different in the two mouse lines (Lazarenko et al., 2009). In addition, each mouse line presents distinct advantages. The greater number of GFP-expressing cells in Jx99 yields increased opportunities for recording in brainstem slices in which the RTN can be unequivocally identified by its anatomic location ventral to the facial motor nucleus. For molecular analysis of dissociated neurons, in which anatomic landmarks are lost, the more restricted expression characteristic of the $\mathrm{B} / \mathrm{G}$ mouse allows confident selection of RTN neurons based on GFP fluorescence. Thus, electrophysiological recordings were typically (but not exclusively) obtained from GFPexpressing RTN neurons of Jx99 mice, whereas molecular analysis was performed only using dissociated RTN neurons derived from B/G mice.

Electrophysiological recordings in brainstem slices. Transverse brainstem slices from neonatal [postnatal day 6 (P6) to P10] Phox2b-eGFP mice were prepared as described previously (Lazarenko et al., 2009). Briefly, mice were anesthetized with ketamine $(375 \mathrm{mg} / \mathrm{kg}$, i.m.) and xylazine ( 25 $\mathrm{mg} / \mathrm{kg}$, i.m.) and rapidly decapitated; brainstems were removed, and slices $(300 \mu \mathrm{m})$ were cut in the coronal plane with a microslicer (DSK 1500E; Dosaka) in ice-cold substituted Ringer's solution containing the following (in mM): 260 sucrose, $3 \mathrm{KCl}, 5 \mathrm{MgCl}_{2}, 1 \mathrm{CaCl}_{2}, 1.25 \mathrm{NaH}_{2} \mathrm{PO}_{4}$, $26 \mathrm{NaHCO}_{3}, 10$ glucose, and 1 kynurenic acid. Slices were incubated for $30 \mathrm{~min}$ at $37^{\circ} \mathrm{C}$ and subsequently at room temperature in a normal Ringer's solution containing the following (in $\mathrm{mM}$ ): $130 \mathrm{NaCl}, 3 \mathrm{KCl}, 2 \mathrm{MgCl}_{2}$,
$2 \mathrm{CaCl}_{2}, 1.25 \mathrm{NaH}_{2} \mathrm{PO}_{4}, 26 \mathrm{NaHCO}_{3}$, and 10 glucose. Both substituted and normal Ringer's solutions were bubbled with $95 \% \mathrm{O}_{2}$ and $5 \% \mathrm{CO}_{2}$.

We targeted the eGFP-fluorescent subpopulation of Phox $2 \mathrm{~b}$ expressing RTN neurons for loose-patch and whole-cell voltage-clamp recordings (Lazarenko et al., 2009). All recordings were obtained from coronal slices in a chamber on a fixed-stage fluorescence microscope with infrared Nomarski optics (Carl Zeiss Axioskop FS); slices were perfused continuously ( $\sim 2 \mathrm{ml} / \mathrm{min}$ ) with a bath solution containing the following (in mM): $140 \mathrm{NaCl}, 3 \mathrm{KCl}, 2 \mathrm{MgCl}_{2}, 2 \mathrm{CaCl}_{2}, 10 \mathrm{HEPES}$, and 10 glucose. We added a mixture of blockers (10 $\mu \mathrm{M}$ CNQX, $10 \mu \mathrm{M}$ bicuculline, and $30 \mu \mathrm{M}$ strychnine) to inhibit fast excitatory (glutamate) and inhibitory transmitters (GABA, glycine). The $\mathrm{pH}$ of the bath solution was adjusted between 7.0 and 8.0 by addition of $\mathrm{HCl}$ or $\mathrm{NaOH}$. For some experiments, we replaced extracellular $\mathrm{Na}^{+}$with equimolar $\mathrm{N}$-methyl D-glucamine $\left(\mathrm{NMDG}^{+}\right)$. All recordings were performed at room temperature. Patch electrodes had a direct current resistance of 3-6 $\mathrm{M} \Omega$ when filled with internal solution containing the following (mM): $120 \mathrm{KCH}_{3} \mathrm{SO}_{3}, 4 \mathrm{NaCl}, 1 \mathrm{MgCl}_{2}$, $0.5 \mathrm{CaCl}_{2}, 10$ HEPES, 10 EGTA, $3 \mathrm{Mg}$-ATP, 0.3 GTP-Tris, and 0.05 ZD-7288 (4-ethylphenylamino-1,2-dimethyl-6-methylaminopyrimidinium chloride), $\mathrm{pH}$ 7.2; electrode tips were coated with Sylgard 184 (Dow Corning). Tetrodotoxin $(1 \mu \mathrm{M})$ was routinely added to the bath for voltage-clamp recordings of isoflurane-sensitive currents.

Recordings were obtained using an Axopatch 200B amplifier and a Digidata 1322A analog-to-digital converter with pClamp 9.0 software (all from Molecular Devices). Firing rate histograms were generated by integrating action potential discharge in $10 \mathrm{~s}$ bins using Spike $5.0 \mathrm{soft}-$ ware (Cambridge Electronic Design). We determined $\mathrm{pH}$ sensitivity of individual RTN neurons by plotting firing rate at different bath $\mathrm{pH}$ and interpolating the $\mathrm{pH}$ value at which firing rate was reduced to half of that obtained at $\mathrm{pH} 7.0\left(\mathrm{pH}_{50}\right)$ by using linear regression analysis (Excel; Microsoft). The frequency distribution plot of $\mathrm{pH}_{50}$ values was fitted with a double Gaussian function using Origin (version 7.0). To characterize anesthetic-sensitive currents under whole-cell voltage clamp, we obtained steady-state current-voltage $(I-V)$ relationships from a holding potential of $-60 \mathrm{mV}$ by applying voltage steps (from -40 to -120 $\mathrm{mV}$, in $10 \mathrm{mV}$ increments) under control conditions and in the presence of isoflurane; isoflurane-sensitive $I-V$ curves were obtained in each cell by subtraction, and the data from individual cells were averaged for presentation.

Neurophysiological experiments in vivo. Experiments were performed on male Sprague Dawley rats $(n=9)$ weighing between 240 and $350 \mathrm{~g}$. General anesthesia was induced with $5 \%$ isoflurane in pure oxygen. Rectal temperature was maintained close to $37.5^{\circ} \mathrm{C}$ with a servo-controlled heating pad. Surgery was performed under artificial ventilation with $3 \%$ isoflurane in pure oxygen $(\sim 1 \mathrm{ml} / 100 \mathrm{~g}, 70-80$ cycles/min). Expired $\mathrm{CO}_{2}$ was monitored with a capnometer (Columbus Instruments), and end-tidal $\mathrm{CO}_{2}\left(\right.$ etCO $\left.\mathrm{CO}_{2}\right)$ was determined from the peak $\mathrm{CO}_{2}$ value registered by the capnometer at the end of expiration, averaged for at least 10 breaths. The rats were subjected to the following surgical procedures, as described previously (Fortuna et al., 2008, 2009): bilateral vagotomy in the neck; femoral artery cannulation for arterial blood pressure (BP) measurements; femoral vein cannulation for fluid and drug administration; phrenic nerve dissection via a dorsolateral approach; and placement of a burr hole in the occipital plate to insert a recording electrode into the left medulla oblongata. Finally, a bipolar stimulation electrode was inserted next to the mandibular branch of the facial nerve to map the facial motor nucleus with antidromic field potentials as a guide to locate the immediately adjacent retrotrapezoid nucleus. During surgery, the adequacy of the anesthesia was gauged by the fact that nociceptive stimuli applied to the tail and hindlegs produced no movement or change in blood pressure.

Before the recording period, isoflurane anesthesia was replaced by urethane. A $10 \%$ urethane solution (in $0.9 \% \mathrm{NaCl}$, i.v.) was injected with a syringe pump at a dose of $1.3-1.5 \mathrm{~g} / \mathrm{kg}$ for a period of $\sim 30 \mathrm{~min}$, while isoflurane was gradually removed. After a period of equilibration during which we verified that the previous anesthesia criteria were still in effect, the rats were given the muscle relaxant pancuronium $(1 \mathrm{mg} / \mathrm{kg}$, i.v. $)$. The level of anesthesia was thereafter gauged by stability of the arterial pressure, absence of phrenic nerve activation during application of a firm tail 
or toe pinch, and a blood pressure response of $<10 \mathrm{mmHg}$ to these same stimuli.

Phrenic nerve discharge (PND) was recorded with a bipolar wire electrode, filtered $(200-3000 \mathrm{~Hz})$, rectified, and integrated as described previously (Mulkey et al., 2004; Fortuna et al., 2009). Unit recordings were made with glass pipettes filled with $2 \mathrm{M} \mathrm{NaCl}(7-12 \mathrm{M} \Omega$ ). All analog data (end-tidal $\mathrm{CO}_{2}, \mathrm{PND}$, and unit activity) were acquired via a micro-1401 digitizer from Cambridge Electronic Design and were processed offline using version 5 of the Spike 2 software (Cambridge Electronic Design) as described previously (Mulkey et al., 2004; Takakura et al., 2006; Moreira et al., 2007). Processing included action potential discrimination, measurement of neuronal discharge rate, and PND "integration" consisting of full-wave rectification and smoothing (time constant of $0.03 \mathrm{~s}$ ).

Before testing effects of isoflurane on RTN discharge and central respiratory output, we first adjusted ventilator rate and volume to lower end-tidal $\mathrm{CO}_{2}$ sufficiently to silence the phrenic nerve. The ventilator was then maintained with those settings thereafter, and various amounts of $\mathrm{CO}_{2}$ were bled into the breathing mixture to increase end-tidal $\mathrm{CO}_{2}$ and achieve different levels of central respiratory drive. Each $\mathrm{CO}_{2}$ level was maintained for $\sim 3-5 \mathrm{~min}$ to reach steady-state respiratory output (RTN neurons and PND), at which time isoflurane was administered from a calibrated vaporizer via the inspirate, and effects on RTN discharge rate, phrenic nerve frequency, and amplitude were determined. To control for isoflurane effects on blood pressure, we administered a sodium nitroprusside (SNP) solution (9 or $18 \mu \mathrm{g} / \mathrm{ml}$ in saline, i.v.) in volumes that were determined to produce the same decrease in blood pressure as that evoked by isoflurane (usually $40-100 \mu \mathrm{l}$ ).

Single-cell reverse transcription-PCR from acutely dissociated GFPexpressing RTN neurons. Neurons were dissociated acutely from neonatal (P7-P10) brainstem slices prepared from B/G Phox $2 \mathrm{~b}-$ eGFP mice, essentially as described previously (Hempel et al., 2007; Lazarenko et al., 2009). After incubation in normal Ringer's solution, slices were placed in an oxygenated chamber (bubbled with $95 \% \mathrm{O}_{2} / 5 \% \mathrm{CO}_{2}$ ) at room temperature containing Pronase (Sigma protease type XIV, $1-2 \mathrm{mg} / \mathrm{ml}$ ) in low-Ca ${ }^{2+}$ Ringer's solution $\left(0.1 \mathrm{~mm} \mathrm{Ca}^{2+}\right)$. After $30 \mathrm{~min}$ of enzyme digestion, the tissue was rinsed multiple times in low-Ca ${ }^{2+}$ Ringer's solution and normal Ringer's solution before transfer to HEPESbuffered bath solution. The RTN region was microdissected and triturated into single-cell suspension by using $300 \mu \mathrm{m}$ fire-polished Pasteur pipettes. The cell suspension was plated into HEPES-based buffer in a chamber on the microscope. Cells were allowed to settle on the floor of chamber for $10 \mathrm{~min}$ at room temperature, and eGFP-positive $\left(\mathrm{eGFP}^{+}\right)$ cells were collected for molecular analysis.

Single-cell reverse transcription (RT)-PCR was performed on dissociated eGFP ${ }^{+}$RTN neurons (Yan and Surmeier, 1996; Lazarenko et al., 2009). In short, baked and silanized pipettes were filled with sterile internal solution containing $10 \times$ RT buffer and RNaseOUT (Superscript III; Invitrogen) and lowered onto eGFP ${ }^{+}$cells visualized on a Carl Zeiss AxioExaminer fluorescence microscope. The $\mathrm{eGFP}^{+}$cells were aspirated into the pipette, and $\sim 1 \mu \mathrm{l}$ of internal solution containing the cytoplasmic contents were expelled into a sterile tube containing dNTPs, BSA, RNaseOUT, oligo-dT, and random hexamers; this pre-RT mixture was incubated at $65^{\circ} \mathrm{C}$ for $5 \mathrm{~min}$, cooled on ice for $1 \mathrm{~min}$, and stored at $-70^{\circ} \mathrm{C}$. First-strand cDNA synthesis was performed with Superscript III Reverse Transcriptase, RNA was digested with RNase $\mathrm{H}$, and cDNA was stored at $-20^{\circ} \mathrm{C}$. Single-cell cDNA was amplified using two rounds of conventional PCR (GoTaq; Promega) with pairs of gene-specific outside (first round) and nested primers (second round) for Phox $2 \mathrm{~b}$, glyceraldehyde-3-phosphate dehydrogenase (GAPDH), VGlut2, GAD1 (GAD67), and THIK-1; all primer pairs were intron spanning (for primer sequences, see supplemental data, available at www.jneurosci.org as supplemental material). The PCR conditions were as follows: $95^{\circ} \mathrm{C}(120 \mathrm{~s})$; 35 cycles of $95^{\circ} \mathrm{C}(40 \mathrm{~s}), 59^{\circ} \mathrm{C}(40 \mathrm{~s})$, and $72^{\circ} \mathrm{C}(20-40 \mathrm{~s}) ; 72^{\circ} \mathrm{C}(300 \mathrm{~s})$. We included negative control reactions with no added template in each experiment; amplification of GAPDH mRNA served as a positive control. PCR products were separated by electrophoresis on agarose gels. Data were only included from experiments in which no PCR product was obtained from the no-template control and from cells in which there was a positive signal for at least one of the genes.
Data acquisition and analysis. Results are presented as mean \pm SEM. Data were analyzed statistically using ANOVA or Student's $t$ test; post hoc pairwise comparisons used Bonferroni's or Holm-Sidak methods. In all cases, differences in mean values were considered significant if $p<0.05$.

\section{Results \\ Inhalational anesthetics increase excitability of RTN chemoreceptor neurons in vitro}

We used cell-attached loose-patch recordings to examine effects of inhalational anesthetics on firing activity of GFP-labeled RTN chemoreceptor neurons in brainstem slices from Phox $2 b-e G F P$ mice (Lazarenko et al., 2009). As depicted for a pH-sensitive RTN neuron in Figure $1 \mathrm{~A}$, bath alkalization from $\mathrm{pH} 7.3$ to $\mathrm{pH} 7.5$ reduced spontaneous discharge, and further alkalization to $\mathrm{pH}$ 7.8 essentially silenced the neuron; firing rate recovered to above control levels during subsequent bath acidification (from $\mathrm{pH} 7.8$ to $\mathrm{pH} 7.0$ ). Application of $2 \%$ isoflurane to this cell at $\mathrm{pH} 7.3$ evoked a marked increase in discharge. Firing rate responses to changes in bath $\mathrm{pH}$ persisted in the continued presence of isoflurane: bath alkalization from $\mathrm{pH} 7.3$ diminished whereas bath acidification increased firing rate from the new, isoflurane-elevated discharge level. Isoflurane increased spontaneous discharge in all RTN neurons tested ( $n=61$, from $2.7 \pm 0.2$ to $4.8 \pm 0.3 \mathrm{~Hz}$ at $\mathrm{pH}$ $7.3 ; p<0.0001)$. The averaged firing rate for a group of RTN neurons tested at different extracellular $\mathrm{pH}$ levels under control conditions and in the presence of isoflurane is plotted in Figure $1 \mathrm{~B}$; note that the increase in firing by isoflurane was similar regardless of prevailing $\mathrm{pH}$, as reflected in virtually identical slopes of regression lines describing the relationship between RTN neuron firing and bath $\mathrm{pH}$ under both conditions (i.e., the $\mathrm{pH}$ sensitivity was not changed by isoflurane).

We previously documented the existence of two populations of spontaneously active chemosensitive RTN neurons in Phox $2 \mathrm{~b}-$ eGFP mice that could be distinguished based on initial firing rates and the $\mathrm{pH}$ range over which the cells maintained firing (Lazarenko et al., 2009): type I cells have lower baseline firing rates and are silenced by mild extracellular alkalization (i.e., to $\mathrm{pH} 7.5$ ), whereas type II cells fire more rapidly under control conditions and require more extreme bath alkalization to cease discharge (i.e., to $\mathrm{pH} 7.8-8.0$ ) (see cell in Fig. $1 A$ ). We determined a $\mathrm{pH}$ value at which the firing rate was reduced by $50 \%$ from the peak discharge obtained at $\mathrm{pH} 7.0$ for each RTN neuron; the frequency distribution of cells based on these derived $\mathrm{pH}_{50}$ values, shown in Figure $1 C$, indicates an approximately equal representation of type I and type II cells in the overall population (type I $<\mathrm{pH}_{50}$ $7.42<$ type II). Again, there was a clear relationship between initial firing rate and $\mathrm{pH}_{50}$ value (Fig. 1D), as described previously (Lazarenko et al., 2009). In addition, for both cell types, we found a similar degree of activation by isoflurane (change in firing rate, $\sim 2 \mathrm{~Hz}$; type I, $2.1 \pm 0.3 \mathrm{~Hz}, n=30$; type II, $2.1 \pm 0.2 \mathrm{~Hz}$, $n=27$ ) and no change in $\mathrm{pH}$ sensitivity by isoflurane in subgroups of type I and type II RTN neurons studied under different bath $\mathrm{pH}$ conditions (Fig. $1 E$ ).

We also examined effects on RTN firing activity of chloralose and urethane, an anesthetic combination commonly used for in vivo experiments in animal models. As shown for the exemplar $\mathrm{pH}$-sensitive RTN neuron in Figure $1 F$, isoflurane caused a strong increase in firing rate to approximately the same level as seen with bath acidification (to $\mathrm{pH}$ 7.0). In contrast, firing was inhibited by chloralose and urethane in the same cell. The neuron retained its $\mathrm{pH}$ sensitivity in the presence of chloralose-urethane because bath acidification to $\mathrm{pH} 7.0$ caused an increase in firing comparable with that seen under acidified conditions before an- 

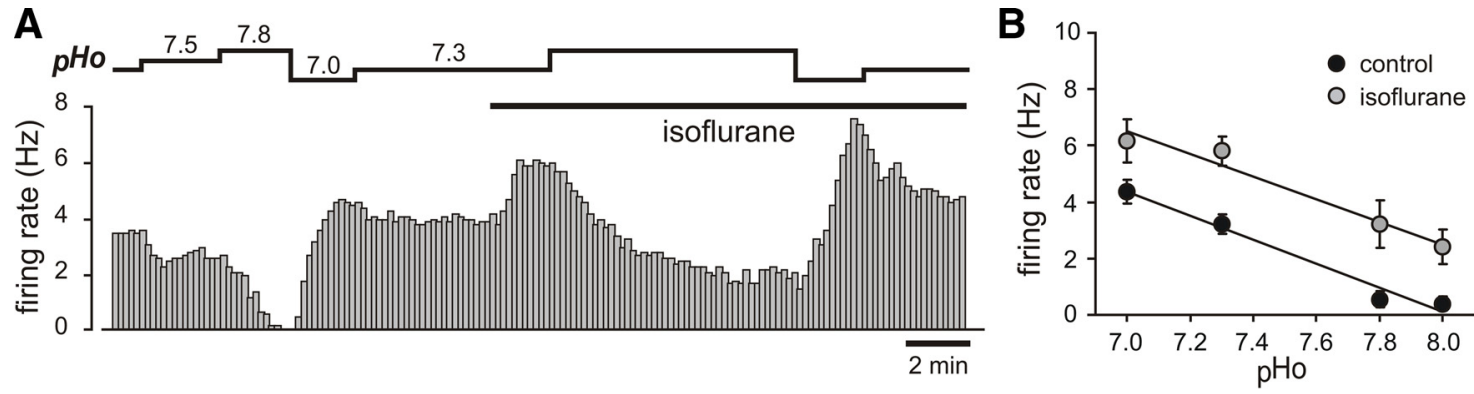



$\mathbf{F}$

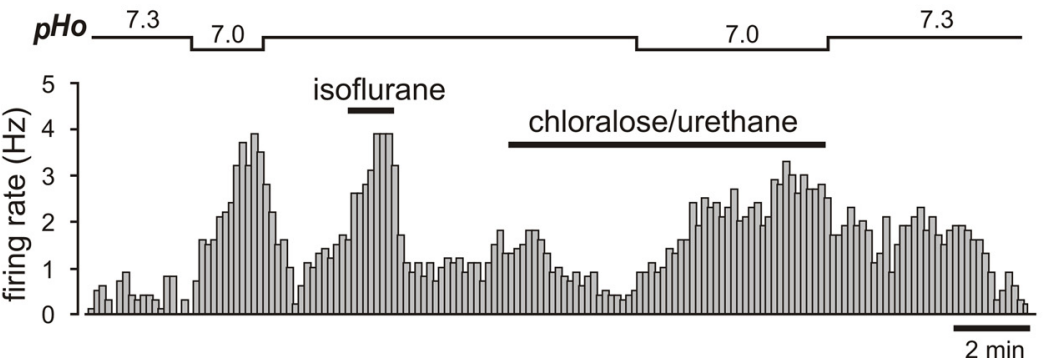

D

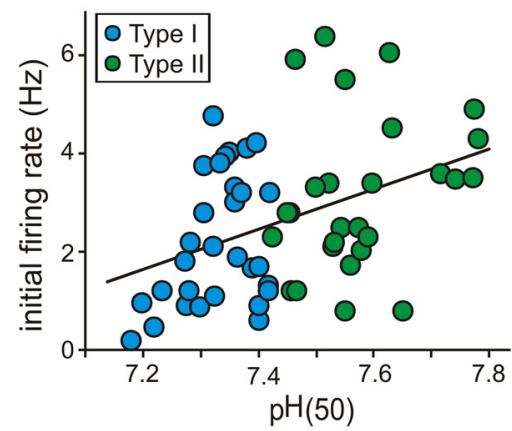

\section{G}

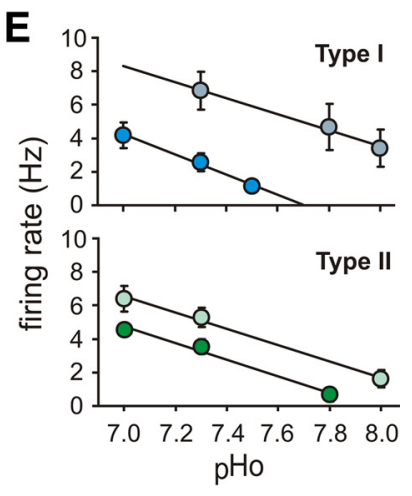

G

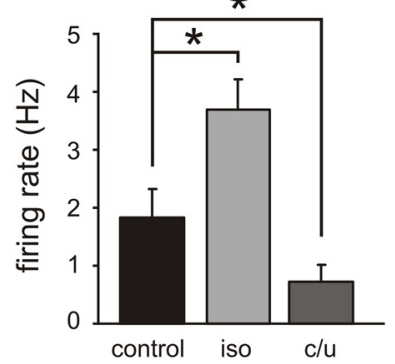

Figure 1. Isoflurane activates chemosensitive RTN neurons. A, Representative loose-patch recording of firing rate in a GFP-expressing mouse RTN neuron (type II cell). From a control pH of 7.3, bath alkalization and bath acidification caused, respectively, decreases and increases in spontaneous firing; $2 \%$ isoflurane increased RTN neuron firing above control levels in pH 7.3, and subsequent changes in bath $\mathrm{pH}$ in the presence of isoflurane had similar effects on firing as under control conditions. $\boldsymbol{B}$, The relationship between firing rate and pH for the subgroup of RTN neurons exposed to multiple pH levels under control conditions and during exposure to isoflurane; the anesthetic caused a parallel upward shift in firing rate (i.e., it did not affect pH sensitivity). $\mathbf{C}$, Biphasic frequency distribution of $\mathrm{pH}_{50}$ values derived for $\mathrm{RTN}$ neurons, with peaks of approximately equal size centered at $\mathrm{pH} 7.38$ and 7.56 ; this distribution was used to assign individual neurons to two groups (type I, $\mathrm{pH}_{50}<7.42$; type II, $\mathrm{pH}_{50}>7.42$ ). D, The relationship between initial firing rate (at pH 7.3) and $\mathrm{pH}_{50}$ for this same subgroup of RTN neurons; note that initial firing rate was typically higher in type II cells that required stronger alkalization to be silenced. $\boldsymbol{E}$, Isoflurane caused a parallel upward shift in firing rate for both type I and type II cells. $F$, Loose-patch recording of firing rate in a $\mathrm{pH}$-sensitive GFP-expressing mouse RTN neuron (type I cell); isoflurane (2\%) increased discharge rate, whereas a chloralose- urethane combination decreased firing. G, Averaged firing rate for RTN neurons examined under control conditions and during exposure to isoflurane (iso) and chloralose- urethane $(c / u)(n=8) .{ }^{*} p<0.05$ versus control.

esthetic exposure (change of $\sim 3 \mathrm{~Hz}$ ). Averaged data revealed a significant decrease in firing rate in the presence of chloraloseurethane (Fig. 1G); a similar effect on RTN neuronal firing was also observed with urethane alone (decreased from $1.7 \pm 0.9$ to $0.7 \pm 0.6 \mathrm{~Hz}, n=4)$.

\section{Anesthetics inhibit a background $\mathrm{K}^{+}$conductance in a subset of RTN chemoreceptor neurons}

The data presented above indicate that isoflurane excites GFPexpressing RTN chemosensitive neurons recorded from Phox 2b-eGFP mice. We performed whole-cell voltage-clamp experiments on these cells to determine the ionic basis for this excitatory effect. Isoflurane induced an inward shift in holding current in nearly all cells ( $\sim 87 \%, n=62$ of 71$)$. In these neurons, the isoflurane-induced inward current was $6.0 \pm 0.8 \mathrm{pA}$ (at -60 $\mathrm{mV}, n=62)$; in the remaining few cells, isoflurane had either little effect or evoked a slight outward current shift $(5.3 \pm 1.0 \mathrm{pA}$ at $-60 \mathrm{mV}, n=9$ ).
For the RTN neuron depicted in Figure $2 A$, the isofluraneinduced current (Fig. $2 A$, top) was associated with a net decrease in conductance (Fig. $2 \mathrm{~A}$, bottom). This type of response to isoflurane (i.e., inward current with decreased conductance) was observed in approximately half the cells studied $(\sim 49 \%, n=35$ of 71 ); it was reminiscent of responses observed in functionally identified chemosensitive RTN neurons in the rat, which we attributed to an isoflurane-evoked decrease in background $\mathrm{K}^{+}$ conductance (Mulkey et al., 2007). Indeed, the averaged isoflurane-inhibited current in this subgroup of GFP-expressing mouse RTN neurons displayed a weakly rectifying $I-V$ profile and reversed near $E_{\mathrm{K}}$ (approximately $-90 \mathrm{mV}$ ), as expected for a background $\mathrm{K}^{+}$current (Fig. $2 B$ ).

It is important to point out that the isoflurane-sensitive inward current was associated with an opposite effect on input conductance in a substantial population of RTN neurons $(\sim 38 \%, n=27$ of 71$)$ : isoflurane caused a net increase rather than a decrease in conductance, implying activation of a cationic 
current component (Fig. 2C). As shown in Figure 2D, when averaged across all RTN neurons, the $I-V$ relationship of isofluranesensitive current showed no clear reversal potential, as expected for contributions from multiple anesthetic-sensitive currents. These different responses to isoflurane did not track with the two types of cells distinguished above based on $\mathrm{pH}_{50}$ values. Isoflurane produced both decreases and increases in input conductance in either type I or type II cells, and the averaged isofluranesensitive $I-V$ relationship for both cell types was similar in shape to that represented in Figure $2 D$ for the entire population (data not shown).

Together, these data indicate that multiple conductances contribute to the net isoflurane-sensitive current in RTN neurons. However, in the subset of these neurons in which isoflurane caused a net decrease in conductance, it appears that inhibition of an anesthetic-sensitive background $\mathrm{K}^{+}$conductance is the predominant ionic mechanism.

\section{RTN neurons express THIK-1 and a THIK-1-like isoflurane-inhibited background $\mathrm{K}^{+}$current}

The $\mathrm{K}_{2 \mathrm{P}}$ family of $\mathrm{K}^{+}$channels contributes to background $\mathrm{K}^{+}$currents in a number of cellular contexts (Lesage and Lazdunski, 2000; Goldstein et al., 2001; Talley et al., 2003). Among $K_{2 P}$ channels that are sensitive to inhalational anesthetics, most show an increase in activity when exposed to the drugs (Patel and Honoré, 2001). The notable exception is THIK-1 or $\mathrm{K}_{2 \mathrm{P}} 13.1$, which is inhibited by inhalational anesthetics (Rajan et al., 2001). Thus, we sought to determine whether THIK-1 is expressed in RTN neurons and whether the properties of the RTN neuronal isoflurane-inhibited $\mathrm{K}^{+}$current resemble those of THIK-1.

In our previous work, we showed that chemosensitive RTN neurons are the only GFP-fluorescent cell population in the caudal brainstem of B/G mice (Lazarenko et al., 2009). Therefore, RTN neurons dissociated from $\mathrm{B} / \mathrm{G}$ mouse brainstem slices could be confidently selected for single-cell RT-PCR based on GFP fluorescence (Fig. 3A, left). We developed a multiplex nested PCR reaction to assay THIK-1 expression in individual RTN neurons while simultaneously examining other genes to verify that selected cells indeed present the glutamatergic, Phox $2 \mathrm{~b}$-expressing phenotype predicted for chemosensitive RTN neurons (Fig. $3 A$, right). As expected, all cells expressed Phox $2 \mathrm{~b}$ and VGlut2, and none expressed GAD1 ( $n=$ 30) (Stornetta et al., 2006); GAPDH amplification verified adequate mRNA extraction, and, for all reactions, control samples without template yielded no amplification product. Importantly, we found clear evidence for expression of THIK-1 in a subgroup of these RTN neurons ( $~ 63 \%, n=19$ of 30$)$; this is slightly greater than the fraction of cells for which the net isoflurane-sensitive $I-V$ resembled a background $\mathrm{K}^{+}$current $(\sim 50 \%)$. In the remaining cells, THIK-1 was either not expressed or present at levels below detection threshold.

We attempted a number of different approaches to evaluate contributions of THIK-1 to the native RTN isoflurane-sensitive current. There are no THIK-1-specific pharmacological tools available, but arachidonic acid was reported to activate recombinant THIK-1 and, at high concentrations ( $1 \mathrm{mM})$, to enhance a native THIK-1-like current (Rajan et al., 2001; Bushell et al., 2002; Campanucci et al., 2005). In our hands, however, arachidonic acid (up to $1 \mathrm{~mm}$ ) failed to consistently or robustly activate recombinant THIK-1 currents in HEK 293 cells (only $32 \pm 6.0 \%$ activation, $n=8$ of 11 cells); moreover, low concentrations of arachidonic acid $(<200 \mu \mathrm{M})$ had variable effects on membrane current in RTN neurons, whereas high concentrations (up to 1 $\mathrm{mm}$ ) appeared to modulate multiple conductances (data not shown).

As an alternative, based on our hypothesis that a cationic conductance might contribute to the overall anesthetic-sensitive current in RTN neurons, we tested whether the relevant $\mathrm{K}^{+}$current would be more evident under conditions when extracellular $\mathrm{Na}^{+}$ was replaced with an impermeant ion. Indeed, this maneuver uncovered an isoflurane-inhibited $\mathrm{K}^{+}$current in all cells tested $(n=9)$, and, interestingly, it also enhanced the anestheticsensitive current amplitude. A representative experiment is provided in Figure 3B. Under control conditions, isoflurane caused a barely detectable shift in holding current; after switching to an NMDG-containing bath solution, holding current became increasingly outward, and, after attaining a new steady holding level, a second exposure to isoflurane evoked a much larger inward current shift. A comparison of the averaged $I-V$ relationships from RTN neurons tested in this manner, shown in Figure $3 B$, illustrates the enhanced isoflurane-sensitive current in the presence of NMDG; it also shows a striking transformation of the properties of the isoflurane-sensitive current, such that the $I-V$ curve obtained in the absence of extracellular $\mathrm{Na}^{+}$takes the form expected for a background $\mathrm{K}^{+}$current.

These data indicate that RTN neurons express an anestheticsensitive background $\mathrm{K}^{+}$current that is activated by removal of 


\section{A dissociated}
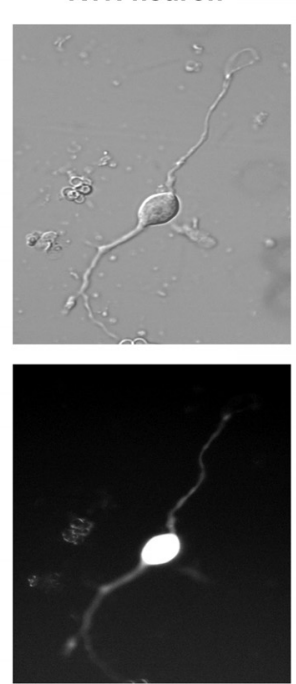

multiplex PCR

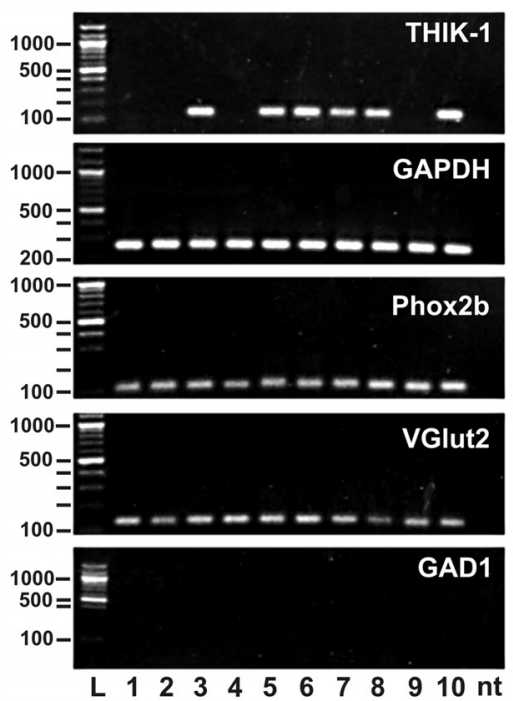

\section{B RTN neuron in slice}


\section{THIK-1 in HEK293 cell}
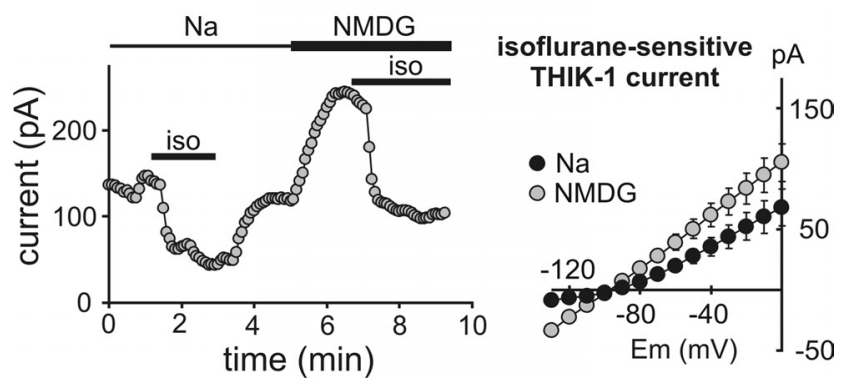

Figure 3. THIK-1-like currents in RTN neurons. $A$, RTN neurons were acutely dissociated from the caudal brainstem of Phox $2 b$ - eGFP mice ( $B / G$ strain) for molecular analysis. Left, A cell with a bipolar profile and extended processes under differential interference contrast optics (top) was identified as an RTN neuron based on GFP fluorescence (bottom). Right, Individual dissociated RTN neurons were selected for multiplex nested RT-PCR to detect expression of THIK-1, GAPDH, Phox2b, VGlut2, and GAD1, as shown for this representative sample of 10 cells (lanes marked 1-10; L, ladder; nt, no template control). THIK-1 expression was found in 6 of the 10 cells in the experiment depicted and in 19 of 30 overall ( $\sim 63 \%)$. All cells expressed Phox $2 \mathrm{~b}$ and VGlut2 and none expressed GAD1. Detection of GAPDH verified successful RNA isolation and the absence of signal in all no-template control reactions ruled out nonspecific amplification. $\boldsymbol{B}$, Left, Voltage-clamp recording of an RTN neuron in a brainstem slice preparation. Holding current was measured during exposure to $2 \%$ isoflurane, first under control conditions and then after substituting extracellular $\mathrm{Na}^{+}{ }^{+}$with NMDG. Note that removal of $\mathrm{Na}$ caused development of a steady outward current and enhanced the size of the isoflurane-induced inward shift in holding current (top). Right, Averaged I-V relationship of the isoflurane-inhibited current (control - isoflurane) in RTN neurons in the presence and absence of extracellular $\mathrm{Na}^{+}(n=9)$. The isoflurane-sensitive current in NMDG is larger and displays properties more closely resembling those expected of a background $\mathrm{K}^{+}$current. C, Left, Voltage-clamp recording of holding current from an HEK293 cell expressing THIK-1 during exposure to $2 \%$ isoflurane in the presence and absence of extracellular $\mathrm{Na}^{+}$. As with the native current in RTN neurons, removal of extracellular $\mathrm{Na}^{+}$enhanced THIK-1 current and increased the isoflurane-sensitive current component. Right, Averaged I-V relationship of isoflurane-inhibited THIK-1 current (control - isoflurane) in the presence and absence of extracellular $\mathrm{Na}^{+}(n=10$ and 25$)$. extracellular $\mathrm{Na}^{+}$. Because this is a property that has not been described previously for THIK-1, we tested whether recombinant THIK-1 currents are also increased by substitution of $\mathrm{Na}^{+}$with NMDG in the bath solution. A recording from an HEK293 cell transfected with THIK-1 is shown in Figure 3C. At the holding potential of $-60 \mathrm{mV}$ under control conditions, THIK-1 currents were inhibited by isoflurane $(2 \%)$; replacement of $\mathrm{Na}^{+}$with NMDG in the bath solution increased THIK-1 channel currents and the size of the anesthetic-sensitive current. Thus, these observations are similar to those obtained in RTN neurons and are consistent with the possibility that THIK-1 contributes to the native anesthetic-sensitive background $\mathrm{K}^{+}$current in those cells.

As noted above, we found that anesthetic modulation of RTN neuron firing was independent of the prevailing $\mathrm{pH}$ (Fig. 1) (Mulkey et al., 2007), suggesting that the underlying anestheticmodulated conductance would be likewise insensitive to $\mathrm{pH}$. Indeed, we found no difference in peak THIK-1 currents in HEK293 cells recorded under control, acidified, or alkalized conditions ( $\mathrm{pH} 7.3,35.8 \pm 6.0 \mathrm{pA} / \mathrm{pF} ; \mathrm{pH} 7.0,34.9 \pm 6.3 \mathrm{pA} / \mathrm{pF} ; \mathrm{pH}$ $8.0,37.0 \pm 4.4 \mathrm{pA} / \mathrm{pF} ; n=14 ; p>0.79)$. Together, these data show that THIK-1 expression can be detected in a majority of RTN neurons, and these cells present with a background $\mathrm{K}^{+}$ current sharing key features of THIK-1 (i.e., suppression by inhalational anesthetics, weak rectification, inhibition by extracellular $\mathrm{Na}^{+}$, and $\mathrm{pH}$ insensitivity). In addition, they suggest that activation of a cationic channel also contributes to the net anesthetic-sensitive current in RTN neurons.

\section{Isoflurane enhances RTN neuron activity in vivo}

The data presented to this point indicate that isoflurane can activate $\mathrm{pH}$-sensitive RTN neurons in neonatal mouse brainstem slices; we were interested in testing whether chemosensitive RTN cells from adult animals are also activated by isoflurane in vivo. For these experiments, extracellular recordings were obtained from RTN neurons in the rostroventrolateral medulla of urethane-anesthetized rats (Mulkey et al., 2004; Fortuna et al., 2009); we simultaneously monitored integrated phrenic nerve discharge (iPND) as a measure of central respiratory output, along with BP. Within the RTN, chemosensitive neurons were identified by their characteristic and robust firing responses to changes in etCO $\mathrm{O}_{2}$ (Mulkey et al., 2004).

An excerpt of a typical experiment from a representative cell is shown in Figure $4 A$. Initially, at low etCO $\mathrm{CO}_{2}$ levels, in which RTN neuronal activity and phrenic discharge were just slightly above threshold, addition of $2 \%$ isoflurane to the inspirate caused a dramatic and sustained increase in RTN neuron firing activity; this was associated with a transient increase in phrenic nerve amplitude and frequency (see arrow) that was followed thereafter by a delayed inhibition. Isoflurane also caused a marked decrease in blood pressure. Two observations suggest that the increased RTN discharge was not secondary to the decrease in blood pressure. First, the kinetics of the changes in RTN firing and blood pressure were very different: RTN firing increased rapidly to peak well before any major decrease in blood pressure. Second, there was essentially no effect on RTN activity when a rapid decrease in blood pressure of comparable magnitude was produced by intravenous SNP.

Under conditions of elevated respiratory drive obtained by raising et $\mathrm{CO}_{2}$, isoflurane retained the ability to increase the firing activity of this RTN neuron (Fig. $4 A, B$ ). In these cases, the early activating effects of isoflurane on phrenic nerve discharge were not as evident (but see below), and the most obvious change was a decrease in phrenic nerve amplitude. For the RTN neuron depicted, we determined firing frequency at various levels of etCO 


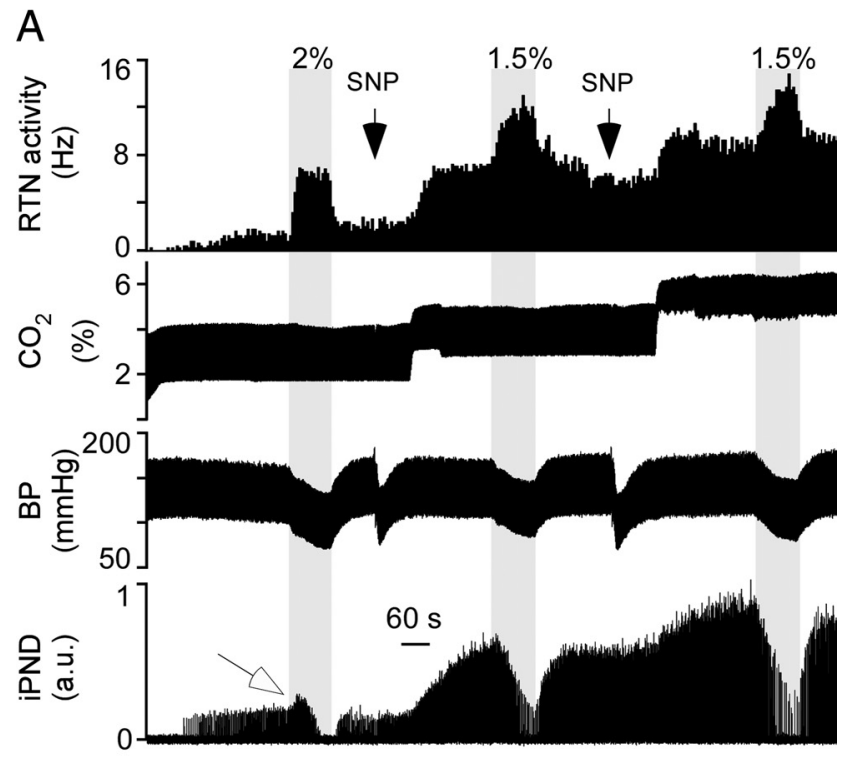

B
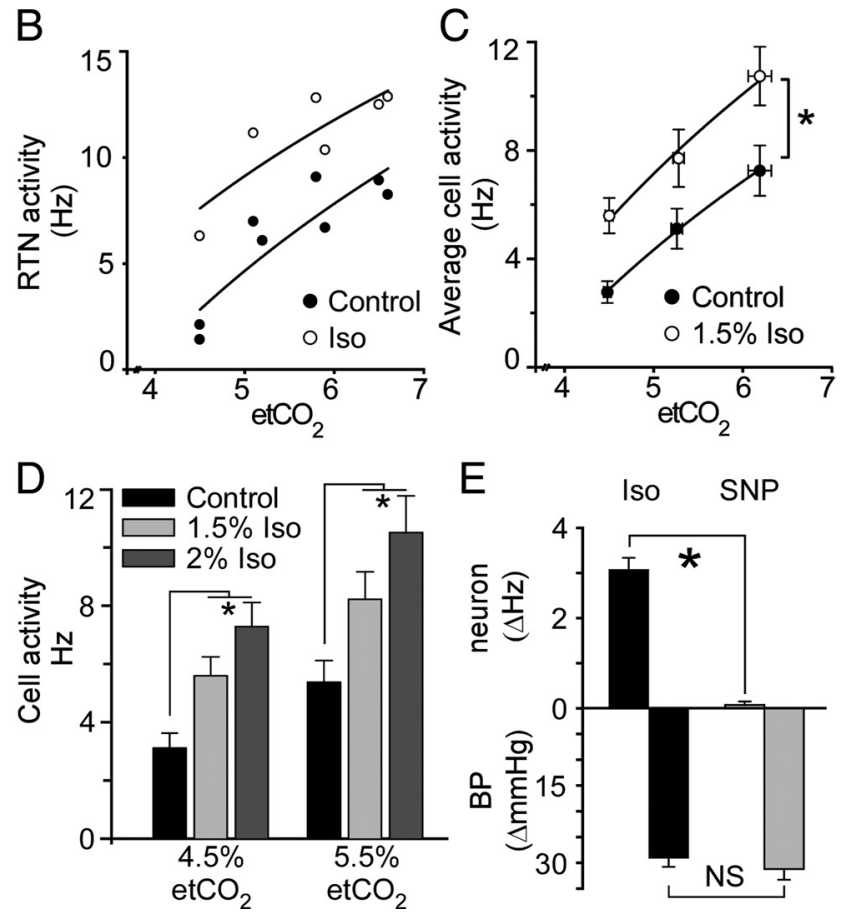

Figure 4. Isoflurane activates RTN neurons in vivo. $\boldsymbol{A}$, Recording of RTN neuronal firing activity, etC $\mathrm{C}_{2}, \mathrm{BP}$, and iPND in a urethane-anesthetized rat during exposure to isoflurane (1.5 and $2 \%$ ) and SNP at different levels of et $\mathrm{CO}_{2}$ and respiratory drive. Isoflurane evoked an increase in RTN firing rate and a decrease in blood pressure at all levels of et $\mathrm{CO}_{2}$, whereas SNP lowered BP with no effect on RTN activity. $\boldsymbol{B}$, Firing activity of a representative RTN neuron (from $\boldsymbol{A}$ ) at various levels of et $\mathrm{C}_{2}$, in the presence and absence of $1.5 \%$ isoflurane. C, Averaged firing rate for all RTN neurons examined before and during exposure to 1.5\% isoflurane at three levels of et $\mathrm{O}_{2}(n=12)$; isoflurane caused a parallel upward shift in the relationship between et $\mathrm{CO}_{2}$ and RTN discharge ( ${ }^{*} p<0.05$, significant main effect of isoflurane by two-way ANOVA). $D$, Effects of isoflurane on RTN firing activity were dose dependent $\left({ }^{*} p<0.05\right.$, significant dose effect of isoflurane by ANOVA; $n=10)$. $\boldsymbol{E}$, Averaged change in firing rate and blood pressure evoked by isoflurane $(1.5 \%)$ and sodium nitroprusside $\left({ }^{*} p<0.05\right.$ by ANOVA; $n=9$ ); SNP decreased BP to the same extent as isoflurane but did not affect RTN discharge.

under control conditions and in the presence of isoflurane (Fig. $4 \mathrm{~B}$ ); the firing rate increase by isoflurane was approximately the same magnitude at all etCO $\mathrm{CO}_{2}$ levels. Similar results were obtained when averaged for all RTN neurons studied (Fig. 4C): isoflurane induced a nearly parallel upward shift in RTN neuronal discharge at three different levels of etCO $\mathrm{C}_{2}$. Note that the effects of isoflurane were concentration dependent, at least over the limited range tested, with slightly greater increases in RTN activity with $2 \%$ isoflurane than with $1.5 \%$ isoflurane (Fig. $4 D$ ). Averaged data also revealed that, despite equivalent decreases in blood pressure induced by isoflurane and SNP, the elevated RTN neuronal discharge was seen only with isoflurane (Fig. $4 E$ ). Together, these data indicate that isoflurane enhances discharge of RTN respiratory chemoreceptor neurons in vivo in a manner that is independent of $\mathrm{pH} / \mathrm{CO}_{2}$; these results are similar to those obtained from RTN neurons in brainstem slices.

\section{Isoflurane has a biphasic effect on respiratory output in urethane-anesthetized rats}

As alluded to above, the effects of isoflurane on integrated central respiratory output in urethane-anesthetized rats were more complex than those on RTN neuron firing activity. Overall effects on phrenic nerve activity were influenced by both isoflurane concentration and the prevailing level of respiratory drive.

At suprathreshold levels of respiratory drive, we generally observed a biphasic effect of isoflurane on phrenic nerve discharge frequency, featuring an early increase in frequency that later subsided during prolonged exposure to isoflurane; as seen in Figure $5 \mathrm{~A}$, the late decrease returned phrenic nerve frequency either to around the initial control level (as with $1.5 \%$ isoflurane) or to below control levels (as with $2 \%$ isoflurane). The decrease in phrenic nerve frequency was usually accompanied by a corresponding slow decline in burst amplitude. In the bottom panels of Figure $5 A$, we quantified effects of 1.5 and $2 \%$ isoflurane measured at relatively high levels of respiratory drive (i.e., phrenic nerve amplitude $>80 \%$ of peak) by averaging phrenic nerve frequency and amplitude under baseline conditions (B), during the early peak $(\mathrm{P})$ and the delayed nadir $(\mathrm{N})$ in phrenic frequency, and then after recovery $(\mathrm{R})$. With both isoflurane concentrations, the early increase in frequency and late decrease in amplitude were statistically significant; at the late time point, phrenic nerve frequency was significantly reduced only by $2 \%$ isoflurane. In terms of overall respiratory neural output (i.e., minute phrenic activity, the product of phrenic frequency and amplitude), these changes resulted in a central respiratory drive that was relatively preserved at early time points by the increased frequency and reduced at later time points attributable to decreased burst amplitude.

The general biphasic pattern of isoflurane effects on phrenic nerve discharge was observed consistently, although important aspects of these typical responses were different at lower levels of respiratory drive. For example, the records in Figure $5 B$ depict an experiment in which phrenic nerve discharge frequency followed the pattern described above (i.e., early rise with subsequent slow decay), but it remained above control levels for the duration of the isoflurane application. In addition, phrenic nerve amplitude was slightly increased above control levels in the presence of isoflurane. So, in this particular preparation, the overall respiratory output was actually elevated throughout the exposure to isoflurane. The bottom panels of Figure $5 B$ depict averaged phrenic nerve responses to $1.5 \%$ isoflurane from experiments in which initial burst amplitude was $<50 \%$ of maximum. In these cases, minute respiratory neural output was significantly increased by isoflurane at the early time point, reflecting the initial increase in frequency and maintained amplitude of phrenic discharge at the start of the exposure; at later time points, the decrease in phrenic amplitude led again to a significant decrease in net respiratory drive. 
A
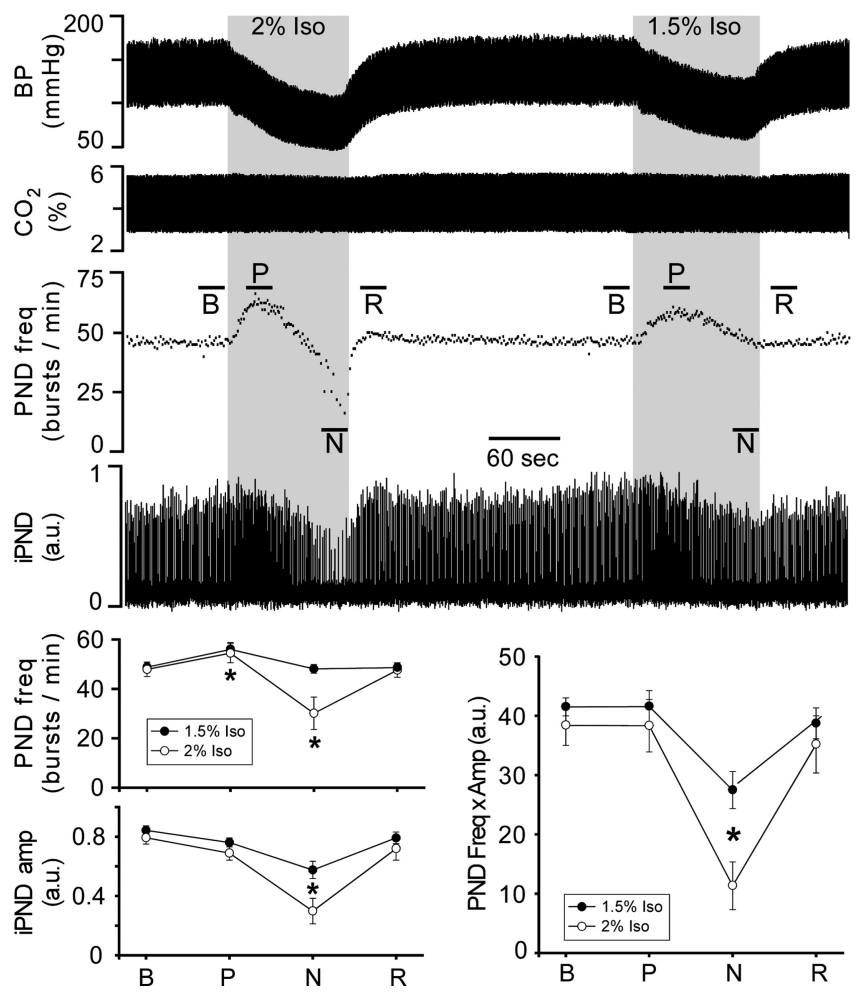

B
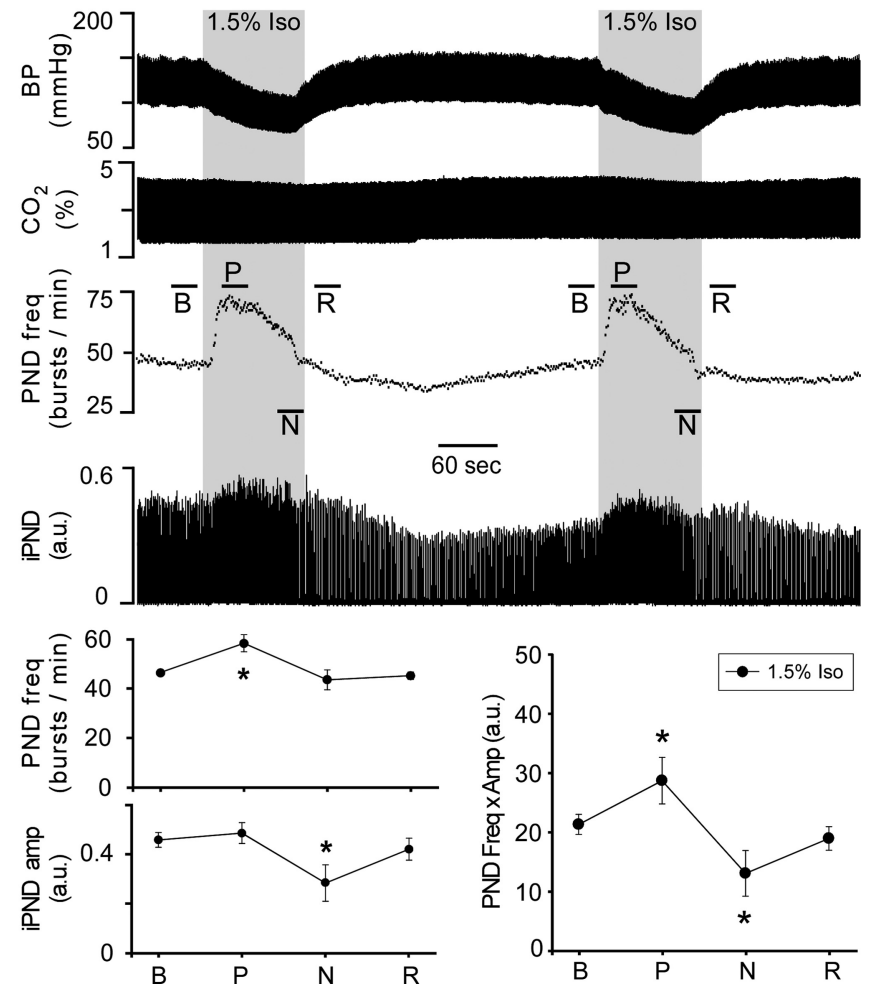

Figure 5. Isoflurane has biphasic effects on respiratory neural output. $A$, Time series depicting effects of isoflurane ( 1.5 and $2 \%)$ on phrenic nerve activity at a relatively high level of etC $\mathrm{O}_{2}$ and respiratory drive. In both cases, isoflurane induced an early, transient increase in respiratory frequency (PND freq) that returned to near (1.5\%) or below (2\%) control levels. A slowly developing decrease in phrenic nerve amplitude most prominently accompanied exposure to $2 \%$ isoflurane. Plots in bottom panels show averaged effects of 1.5 and $2 \%$ isoflurane on frequency and amplitude of phrenic nerve bursts (left) and their product (minute neural output, right) under baseline conditions (B), at the peak (P) and nadir (N) of the respiratory response to isoflurane, and then after recovery $(R)$. The increased frequency maintained baseline respiratory neural output early in the isoflurane exposure, whereas later decreases in frequency and amplitude accounted for reduced central drive at later time points. $\boldsymbol{B}$, Data from a different preparation in which effects of $1.5 \%$ isoflurane were examined at a lower level of respiratory drive (presented as in $\boldsymbol{A}$ ). Note that, under these conditions, averaged minute respiratory output was elevated above baseline by isoflurane at the peak before the secondary decrease. ${ }^{*} p<0.05$ vs baseline conditions by one-way repeatedmeasures ANOVA; data from 8 rats were included in these analyses).

The ability of isoflurane to enhance respiratory output was observed most dramatically under conditions when $\mathrm{CO}_{2}$ levels were lowered even further, to just below the threshold for phrenic nerve activity, as shown in Figure 6. After silencing respiratory output in this preparation, $1.5 \%$ isoflurane increased phrenic nerve activity above threshold via increases in both frequency and amplitude. The effect of isoflurane was again biphasic, but the early increase in respiratory output was striking. Interestingly, the averaged $\mathrm{CO}_{2}$ threshold for respiratory activity was systematically lower in rats anesthetized with isoflurane than in animals anesthetized with either a chloralose- urethane combination or urethane alone (Table 1). This is consistent with activation of RTN neurons by isoflurane, but not chloralose-urethane (Fig. 1), and also with the ability of isoflurane to initiate breathing under conditions when overall respiratory drive is reduced to subthreshold levels.

\section{Discussion}

The glutamatergic, Phox2b-expressing neurons of the RTN provide a $\mathrm{CO}_{2}$-dependent excitatory drive to brainstem circuits controlling respiration (Feldman et al., 2003; Abbott et al., 2009; Guyenet et al., 2009). Under anesthesia, the excitatory drive from these RTN neurons is required for the respiratory network to be active (Takakura et al., 2008). The present study demonstrates that the inhalational anesthetic isoflurane robustly activates the chemosensitive RTN neurons independently of the level of $\mathrm{CO}_{2}$. We found that isoflurane increases spike firing of neonatal mouse
RTN neurons in vitro and adult rat RTN neurons in vivo. We also found that multiple ionic mechanisms contribute to RTN neuronal excitation by isoflurane, including the following: (1) activation of an unidentified cationic current, and (2) inhibition of a background $\mathrm{K}^{+}$current displaying properties consistent with THIK-1, an anesthetic-inhibited $\mathrm{K}_{2 \mathrm{P}}$ channel that we readily detected in a majority of RTN neurons. The overall effect of isoflurane on central respiratory output in urethane-anesthetized rats was complex and dependent on both isoflurane concentration and prevailing respiratory drive. However, it was always characterized by an early increase in phrenic nerve discharge frequency and a later decrease in phrenic burst amplitude. At low levels of etCO $\mathrm{C}_{2}$, when phrenic nerve discharge was initially silent, isoflurane actually raised respiratory drive to beyond the threshold for phrenic nerve activity.

In short, isoflurane enhances the excitatory drive to the respiratory system that originates from the RTN chemoreceptors, and we suggest that this effect offsets, at least partially, the anestheticmediated inhibition of other respiratory-related cell groups (Sirois et al., 2000; Koizumi et al., 2010). Such a mechanism may account for the ability of the respiratory motor system to maintain ventilation even under a surgical plane of anesthesia, when most other motor systems are strongly inhibited (Sonner et al., 2003; Rudolph and Antkowiak, 2004; Grasshoff et al., 2005; Franks, 2008). 
Excitatory and inhibitory neuronal effects of anesthetics influence overall central respiratory output

Our conclusion that inhalational anesthetics can actually enhance respiratory drive via actions on central respiratory chemoreceptor neurons of the RTN seems at odds with the well known depression of breathing and the blunting of respiratory chemoreflexes that occurs during anesthesia (Evers et al., 2006). Clearly, an integrated respiratory output involves numerous brainstem neurons (Feldman et al., 2003), and, of course, anesthetics have actions on multiple molecular targets at various central sites ( $\mathrm{Ru}-$ dolph and Antkowiak, 2004; Grasshoff et al., 2005; Franks, 2008). For motor systems in general, inhalational anesthetics enhance fast inhibitory neurotransmission and depress fast excitatory transmission onto motoneurons (Kendig, 2002; Sonner et al., 2003). In addition, inhalational anesthetics activate TWIK-related acid-sensitive $\mathrm{K}^{+}$(TASK) channels to inhibit brainstem aminergic neurons (Sirois et al., 2000; Washburn et al., 2002), which can cause an indirect disfacilitation of motoneurons; likewise, TASK channel activation in motoneurons results in a direct inhibition by those same anesthetics (Sirois et al., 2000). In the specific case of the respiratory motor system, it was recently found that inhaled anesthetics activate a TASK-like current in pre-Bötzinger neuronal pacemaker neurons (Koizumi et al., 2010); this mechanism was associated with depressed respiratory output in a brainstem slice and was sufficient to account for respiratory depression in a computational network model of the respiratory system (Koizumi et al., 2010). So, there is no doubt that inhalational anesthetics can act at a number of sites within the brainstem and spinal cord, downstream of the RTN, to inhibit many of the neuronal cell groups that serve to generate the respiratory rhythm and/or convey that onward to the muscles of breathing.

The dichotomous effects of isoflurane to enhance RTN neuronal activity while also inhibiting other aspects of the respiratory system likely accounts for the biphasic effects of the anesthetic we observed on respiratory output in vivo: initial activation followed by later inhibition. The fact that isoflurane invariably increased respiratory frequency implies that those actions are mediated at sites antecedent to the respiratory CPG. This is consistent with the possibility that it reflects isoflurane-mediated activation of RTN neurons because current ideas place those cells upstream of the respiratory CPG (Feldman et al., 2003; Guyenet et al., 2009). In contrast, the subsequent decrease in phrenic burst amplitude could occur anywhere within the neural system, from upstream of the CPG through to the final output motoneurons. It is important to acknowledge that the net effect of isoflurane we observed on respiratory activity at steady state was inhibition. Although this supports conventional wisdom that inhalational anesthetics inhibit breathing (Evers et al., 2006), which is most certainly correct, it does not rule out the possibility that the isofluraneinduced inhibition of respiratory output would have been more profound were it not for concomitant excitatory effects of isoflurane on RTN neurons. Unfortunately, there is no way at present to parse contributions of these opposing effects of inhalational
Table 1. $\mathrm{CO}_{2}$ threshold for RTN firing and phrenic nerve discharge in rats anesthetized with three different anesthetics

\begin{tabular}{llll}
\hline & Isoflurane & Urethane & Urethane + chloralose \\
\hline RTN firing & $2.8 \pm 0.1(17)$ & $3.9 \pm 0.1(28)^{*}$ & $5.2 \pm 0.1(14)^{*}$ \\
Phrenic discharge & $3.5 \pm 0.2(13)$ & $4.4 \pm 0.0(21)^{*}$ & $5.7 \pm 0.1(14)^{*}$ \\
\hline
\end{tabular}

Values are averaged minimum end-tidal $\mathrm{CO}_{2}$ levels ( \pm SEM) at which RTN neurons began firing or phrenic nerve discharge became evident ( $n$ provided in parentheses). Averages include historical data obtained under identical conditions for isoflurane (from Fortuna et al., 2009) and for chloralose-urethane (from Takakura et al., 2008); in all cases, adequate anesthesia was assessed by the absence of blood pressure or phrenic nerve response to application of a firm tail or toe pinch. ${ }^{*} p<0.05$, different from isoflurane.

anesthetics on respiratory output in vivo or to examine effects of those drugs when RTN neuronal excitation is blocked.

THIK-1 channel inhibition contributes to anesthetic-induced activation of RTN neurons

Our voltage-clamp analysis of isoflurane-sensitive currents in vitro identified distinct ionic mechanisms that contribute to anesthetic activation of $\mathrm{pH}$-sensitive RTN neurons: an anestheticinhibited background $\mathrm{K}^{+}$current and an anesthetic-activated $\mathrm{Na}^{+}$-dependent current. In approximately half of the RTN neurons tested, isoflurane induced an inward current with decreased conductance; in those neurons, the $I-V$ curves of total anestheticsensitive current had a weakly rectifying profile and reversal potential consistent with inhibition of $\mathrm{K}^{+}$current as the predominant mechanism (Mulkey et al., 2007). Aside from its inhibition by anesthetic, this background $\mathrm{K}^{+}$current shared a number of properties with the $\mathrm{K}_{2 \mathrm{P}}$ channel THIK-1 (Rajan et al., 2001), and, moreover, we were able to show by single-cell RT-PCR that THIK-1 transcripts were present in $\sim 63 \%$ of RTN neurons. In the other group of RTN neurons, the corresponding $I-V$ curves were less informative, with no clear reversal of the anestheticsensitive current. However, an underlying $\mathrm{K}^{+}$current was revealed when extracellular $\mathrm{Na}^{+}$was replaced with NMDG, suggesting that it was obscured by the $\mathrm{Na}^{+}$-dependent current component in those cells. Again consistent with a role for THIK-1, we found that both the native RTN anesthetic-inhibited 
$\mathrm{K}^{+}$current and recombinant THIK-1 were strongly enhanced by removal of extracellular $\mathrm{Na}^{+}$. It is noteworthy that $\mathrm{Na}^{+}$substitution enhanced the $\mathrm{K}^{+}$current in all cells tested, suggesting that THIK-1 may have been expressed at levels below detection threshold in the $\sim 37 \%$ of RTN neurons that appeared negative by single-cell RT-PCR. The molecular identity of the channel that underlies the anesthetic-activated $\mathrm{Na}^{+}$-dependent current remains to be determined. In this respect, it is interesting that anesthetic sensitivity is strongly affected in both Drosophila melanogaster and Caenorhabditis elegans by genetic disruption of, respectively, NA or NCA-1/NCA-2 (Humphrey et al., 2007); these genes are the orthologs of mouse Nalcn, which encodes a mammalian leak sodium channel that is required for respiratory function (Lu et al., 2007).

\section{THIK-1 is not the $\mathrm{pH}$-sensitive background $\mathrm{K}^{+}$channel in RTN neurons}

The mechanism of $\mathrm{pH}$ sensitivity in RTN neurons remains to be determined. Our work has identified an anesthetic-inhibited, THIK-1-like background $\mathrm{K}^{+}$current in RTN neurons (Mulkey et al., 2007), but neither the native neuronal anesthetic-sensitive current nor THIK-1 are influenced by changes in pH (Rajan et al., 2001). Indeed, the isoflurane-enhanced firing of RTN neurons was independent of prevailing $\mathrm{pH}$ or $\mathrm{CO}_{2}$, in vitro and in vivo. The $\mathrm{pH}$-sensitive background $\mathrm{K}^{+}$current in RTN neurons is not attributable to TASK-1 $\left(\mathrm{K}_{2 \mathrm{P}} 3.1\right)$ or TASK-3 $\left(\mathrm{K}_{2 \mathrm{P}} 9.1\right)$ because it was unaffected by halothane, which activates these TASK channels (Patel and Honoré, 2001) and was preserved in mice deleted for either or both of those channels (Mulkey et al., 2007). In recent work, a strikingly specific expression of TASK-2 $\left(\mathrm{K}_{2 \mathrm{P}} 5.1\right)$ was noted in RTN neurons, and, interestingly, mice deleted for that channel presented with disrupted ventilatory responses to $\mathrm{CO}_{2}$ and $\mathrm{O}_{2}$ (Gestreau et al., 2010). It remains to be determined whether TASK-2 accounts for the pH sensitivity of RTN neurons. In this respect, however, it is worth noting that, whereas TASK-2 is $\mathrm{pH}$ sensitive (i.e., activated by extracellular alkalization) (Reyes et al., 1998), it is also activated by inhalational anesthetics (Gray et al., 2000). So, our demonstration here that isoflurane did not affect the $\mathrm{pH}$ dependence of RTN firing, along with previous work indicating that $\mathrm{RTN} \mathrm{pH}$-sensitive background $\mathrm{K}^{+}$currents were identical in the presence and absence of halothane (Mulkey et al., 2007), suggests that TASK-2 does not play a major role in establishing the $\mathrm{pH}$ sensitivity of RTN neurons. However, this does not rule out a contribution for TASK-2 in regulating the intrinsic excitability of RTN neurons and thus their ability to mediate respiratory responses to $\mathrm{CO}_{2}$ and $\mathrm{O}_{2}$ (Gestreau et al., 2010).

In conclusion, this work reveals a novel action of inhalational anesthetics to increase firing activity of RTN respiratory chemoreceptor neurons at any given level of $\mathrm{CO}_{2}$, thereby providing increased excitatory drive to the respiratory control network under conditions when other elements of the system are generally depressed. We propose that this fortuitous activation of RTN neurons supports maintained breathing under deep surgical anesthesia, when other motor systems are completely immobilized.

\section{References}

Abbott SB, Stornetta RL, Fortuna MG, Depuy SD, West GH, Harris TE, Guyenet PG (2009) Photostimulation of retrotrapezoid nucleus phox $2 \mathrm{~b}$-expressing neurons in vivo produces long-lasting activation of breathing in rats. J Neurosci 29:5806-5819.

Bushell T, Clarke C, Mathie A, Robertson B (2002) Pharmacological characterization of a non-inactivating outward current observed in mouse cerebellar Purkinje neurones. Br J Pharmacol 135:705-712.
Campanucci VA, Brown ST, Hudasek K, O’Kelly IM, Nurse CA, Fearon IM (2005) $\mathrm{O}_{2}$ sensing by recombinant TWIK-related halothane-inhibitable $\mathrm{K}^{+}$channel-1 background $\mathrm{K}^{+}$channels heterologously expressed in human embryonic kidney cells. Neuroscience 135:1087-1094.

Eger EI 2nd, Koblin DD, Harris RA, Kendig JJ, Pohorille A, Halsey MJ, Trudell JR (1997) Hypothesis: inhaled anesthetics produce immobility and amnesia by different mechanisms at different sites. Anesth Analg 84:915-918.

Evers AS, Crowder CM, Balser JR (2006) General anesthetics. In: Goodman and Gilman's the pharmacological basis of therapeutics (Brunton LL, Lazo JS, Parker KL, eds), pp 341-368. New York: McGraw-Hill.

Feldman JL, Mitchell GS, Nattie EE (2003) Breathing: rhythmicity, plasticity, chemosensitivity. Annu Rev Neurosci 26:239-266.

Fortuna MG, West GH, Stornetta RL, Guyenet PG (2008) Botzinger expiratory-augmenting neurons and the parafacial respiratory group. J Neurosci 28:2506-2515.

Fortuna MG, Stornetta RL, West GH, Guyenet PG (2009) Activation of the retrotrapezoid nucleus by posterior hypothalamic stimulation. J Physiol 587:5121-5138.

Franks NP (2008) General anaesthesia: from molecular targets to neuronal pathways of sleep and arousal. Nat Rev Neurosci 9:370-386.

Gestreau C, Heitzmann D, Thomas J, Dubreuil V, Bandulik S, Reichold M, Bendahhou S, Pierson P, Sterner C, Peyronnet-Roux J, Benfriha C, Tegtmeier I, Ehnes H, Georgieff M, Lesage F, Brunet JF, Goridis C, Warth $\mathrm{R}$, Barhanin J (2010) Task2 potassium channels set central respiratory $\mathrm{CO}_{2}$ and $\mathrm{O}_{2}$ sensitivity. Proc Natl Acad Sci U S A 107:2325-2330.

Goldstein SA, Bockenhauer D, O'Kelly I, Zilberberg N (2001) Potassium leak channels and the KCNK family of two-P-domain subunits. Nat Rev Neurosci 2:175-184.

Grasshoff C, Rudolph U, Antkowiak B (2005) Molecular and systemic mechanisms of general anaesthesia: the "multi-site and multiple mechanisms" concept. Curr Opin Anaesthesiol 18:386-391.

Gray AT, Zhao BB, Kindler CH, Winegar BD, Mazurek MJ, Xu J, Chavez RA, Forsayeth JR, Yost CS (2000) Volatile anesthetics activate the human tandem pore domain baseline $\mathrm{K}^{+}$channel KCNK5. Anesthesiology 92:1722-1730.

Guyenet PG, Bayliss DA, Stornetta RL, Fortuna MG, Abbott SB, DePuy SD (2009) Retrotrapezoid nucleus, respiratory chemosensitivity and breathing automaticity. Respir Physiol Neurobiol 168:59-68.

Hempel CM, Sugino K, Nelson SB (2007) A manual method for the purification of fluorescently labeled neurons from the mammalian brain. Nat Protoc 2:2924-2929.

Humphrey JA, Hamming KS, Thacker CM, Scott RL, Sedensky MM, Snutch TP, Morgan PG, Nash HA (2007) A putative cation channel and its novel regulator: cross-species conservation of effects on general anesthesia. Curr Biol 17:624-629.

Kendig JJ (2002) In vitro networks: subcortical mechanisms of anaesthetic action. Br J Anaesth 89:91-101.

Koizumi H, Smerin SE, Yamanishi T, Moorjani BR, Zhang R, Smith JC (2010) TASK channels contribute to the $\mathrm{K}^{+}$-dominated leak current regulating respiratory rhythm generation in vitro. J Neurosci 30:4273-4284.

Lazarenko RM, Milner TA, Depuy SD, Stornetta RL, West GH, Kievits JA, Bayliss DA, Guyenet PG (2009) Acid sensitivity and ultrastructure of the retrotrapezoid nucleus in Phox2b-eGFP transgenic mice. J Comp Neurol 517:69-86

Lesage F, Lazdunski M (2000) Molecular and functional properties of twopore-domain potassium channels. Am J Physiol Renal Physiol 279:F793-F801.

Lu B, Su Y, Das S, Liu J, Xia J, Ren D (2007) The neuronal channel NALCN contributes resting sodium permeability and is required for normal respiratory rhythm. Cell 129:371-383.

Moreira TS, Takakura AC, Colombari E, West GH, Guyenet PG (2007) Inhibitory input from slowly adapting lung stretch receptors to retrotrapezoid nucleus chemoreceptors. J Physiol 580:285-300.

Mulkey DK, Stornetta RL, Weston MC, Simmons JR, Parker A, Bayliss DA, Guyenet PG (2004) Respiratory control by ventral surface chemoreceptor neurons in rats. Nat Neurosci 7:1360-1369.

Mulkey DK, Talley EM, Stornetta RL, Siegel AR, West GH, Chen X, Sen N, Mistry AM, Guyenet PG, Bayliss DA (2007) TASK channels determine $\mathrm{pH}$ sensitivity in select respiratory neurons but do not contribute to central respiratory chemosensitivity. J Neurosci 27:14049-14058. 
Patel AJ, Honoré E (2001) Anesthetic-sensitive 2P domain $\mathrm{K}^{+}$channels. Anesthesiology 95:1013-1021.

Rajan S, Wischmeyer E, Karschin C, Preisig-Müller R, Grzeschik KH, Daut J, Karschin A, Derst C (2001) THIK-1 and THIK-2, a novel subfamily of tandem pore domain $\mathrm{K}^{+}$channels. J Biol Chem 276:7302-7311.

Reyes R, Duprat F, Lesage F, Fink M, Salinas M, Farman N, Lazdunski M (1998) Cloning and expression of a novel $\mathrm{pH}$-sensitive two pore domain $\mathrm{K}^{+}$channel from human kidney. J Biol Chem 273:30863-30869.

Rudolph U, Antkowiak B (2004) Molecular and neuronal substrates for general anaesthetics. Nat Rev Neurosci 5:709-720.

Sirois JE, Lei Q, Talley EM, Lynch C 3rd, Bayliss DA (2000) The TASK-1 two-pore domain $\mathrm{K}^{+}$channel is a molecular substrate for neuronal effects of inhalation anesthetics. J Neurosci 20:6347-6354.

Sonner JM, Antognini JF, Dutton RC, Flood P, Gray AT, Harris RA, Homanics GE, Kendig J, Orser B, Raines DE, Rampil IJ, Trudell J, Vissel B, Eger EI 2nd (2003) Inhaled anesthetics and immobility: mechanisms, mysteries, and minimum alveolar anesthetic concentration. Anesth Analg 97:718-740.

Stornetta RL, Moreira TS, Takakura AC, Kang BJ, Chang DA, West GH,
Brunet JF, Mulkey DK, Bayliss DA, Guyenet PG (2006) Expression of Phox $2 \mathrm{~b}$ by brainstem neurons involved in chemosensory integration in the adult rat. J Neurosci 26:10305-10314.

Takakura AC, Moreira TS, Colombari E, West GH, Stornetta RL, Guyenet PG (2006) Peripheral chemoreceptor inputs to retrotrapezoid nucleus (RTN) $\mathrm{CO}_{2}$-sensitive neurons in rats. J Physiol 572:503-523.

Takakura AC, Moreira TS, Stornetta RL, West GH, Gwilt JM, Guyenet PG (2008) Selective lesion of retrotrapezoid Phox2b-expressing neurons raises the apnoeic threshold in rats. J Physiol 586:2975-2991.

Talley EM, Sirois JE, Lei Q, Bayliss DA (2003) Two-pore-Domain (KCNK) potassium channels: dynamic roles in neuronal function. Neuroscientist 9:46-56.

Washburn CP, Sirois JE, Talley EM, Guyenet PG, Bayliss DA (2002) Serotonergic raphe neurons express TASK channel transcripts and a TASK-like $\mathrm{pH}-$ and halothane-sensitive $\mathrm{K}^{+}$conductance. J Neurosci 22:1256-1265.

Yan Z, Surmeier DJ (1996) Muscarinic $(\mathrm{m} 2 / \mathrm{m} 4)$ receptors reduce N- and P-type $\mathrm{Ca}^{2+}$ currents in rat neostriatal cholinergic interneurons through a fast, membrane-delimited, G-protein pathway. J Neurosci 16:2592-2604. 